\title{
Hand dysfunction in scleroderma patients
}

\author{
Disfunção da mão em pacientes com esclerodermia
}

\author{
Thelma Larocca Skare', Bruna Leticia Toebe" , Carla Boros"'I
}

'MD, PhD. Head of Rheumatology Service,

Hospital Universitário Evangélico de Curitiba, Curitiba, Paraná, Brazil.

"MD. Rheumatology Service, Hospital

Universitário Evangélico de Curitiba, Curitiba, Paraná, Brazil.

"'MD. Rheumatology Service, Hospital Universitário Evangélico de Curitiba, Curitiba, Paraná, Brazil.

\author{
To the editor
}

Scleroderma is a disease characterized by functional and structural abnormalities in blood vessels and fibrous involvement of skin and internal organs. ${ }^{1}$ Although the treatment effort is directed mostly against visceral lesions that can diminish life expectancy, scleroderma patients may also experience difficulties with less serious organ damage. Scleroderma patients may present hand dysfunctions that cause difficulties in performing daily activities. Hand dysfunction in scleroderma cases may be caused by RP (Raynaud phenomenon) with finger ulcers, ${ }^{1}$ arthralgia, arthritis, tendonitis, ${ }^{1}$ weakness ${ }^{2}$ and skin thickening, which cause loss of dexterity. ${ }^{1,2} \mathrm{Nacci}$ et al. ${ }^{1}$ observed that the most limiting determinant was joint involvement. Others ${ }^{3}$ observed that rigidity, RP and weakness were the major contributors.

We studied hand dysfunction in 46 patients with scleroderma (four males and 42 females; mean age of 50.5 years; mean disease duration of 7.4 years). Twenty-nine presented the limited form, 11 presented the diffuse form and six cases overlapped with other connective tissue diseases. In this sample, $28.2 \%$ were employed workers; $10.8 \%$ were homemakers; $36.9 \%$ had retired due to health problems; and $15.2 \%$ had retired because of age. The patients were asked about the presence of hand symptoms and answered the Dreiser index questionnaire. ${ }^{4}$ This questionnaire contains 11 questions about activities of daily living. It is measured through a Likert scale ( 0 = no difficulty; 1 = slight difficulty; 2 = moderate difficulty; 3 = impossible to perform) and ranges from 0 (no dysfunction) to 33 (maximum dysfunction). It was initially created to evaluate hand osteoarthritis but has also been used in scleroderma cases. ${ }^{1}$ Patients with pain and stiffness were asked to grade their symptoms through a visual analogue scale (VAS) on which 0 corresponded to no symptoms and 10 to the maximum symptoms.

We found the following: RP in 93.5\%; arthritis (present or previous) in 73.9\%; hand stiffness in $73.9 \%$; pain in the hand (overall) in $71.73 \%$; arthralgia in $65.2 \%$; skin ulcerations (present or previous) in 58.6\%; and calcinosis in $26.6 \%$. The Dreiser index results ranged from 0 to 25 (mean: $8.69 \pm 8.02$ ). The association between the Dreiser index and hand symptoms is shown in Table 1.

The mean VAS obtained for pain in the hand was $7.12 \pm 2.26$ and for stiffness, it was $6.17 \pm 2.05$. There were positive correlations between the Dreiser index values and the VAS for pain $(\mathrm{r}=0.47 ; \mathrm{P}=0.006)$ and between the index and the VAS for stiffness $(\mathrm{r}=0.69$; $\mathrm{P}<0.0001)$.

Hand dysfunction is not always taken into account in scleroderma cases, but RobertsThomson et al. ${ }^{5}$ showed that it can be as incapacitating as in rheumatoid arthritis.

We found that pain and stiffness were the symptoms that most affected functionality. Every effort should be directed towards treating these symptoms, in order to improve scleroderma patients' wellbeing. 
Table 1. Associations between Dreiser index and presence of hand signs and symptoms and autoantibody profile for scleroderma

\begin{tabular}{lccc|} 
& $\begin{array}{c}\text { With the symptom } \\
\text { (mean Dreiser } \pm \text { SD) }\end{array}$ & $\begin{array}{c}\text { Without the } \\
\text { symptom } \\
\text { (mean Dreiser } \pm \text { SD) }\end{array}$ & P \\
Raynaud & $9.0 \pm 8.1$ & $4.3 \pm 5.1$ & 0.35 \\
\hline Ulcerations & $9.6 \pm 8.14$ & $7.3 \pm 7.8$ & 0.35 \\
\hline Arthralgia & $11.8 \pm 7.8$ & $2.1 \pm 2.7$ & $<0.0001$ \\
\hline Arthritis & $9.9 \pm 8.0$ & $6.3 \pm 7.6$ & 0.15 \\
Calcinosis & $10.5 \pm 9.3$ & $8.0 \pm 7.5$ & 0.34 \\
Stiffness & $10.2 \pm 7.3$ & $4.3 \pm 8.6$ & 0.003 \\
\hline Pain in the hand & $11.5 \pm 7.6$ & $1.3 \pm 2.1$ & $<0.0001$ \\
\hline
\end{tabular}

$\mathrm{SD}=$ standard deviation.

\section{REFERENCES}

1. Nacci F, Righi A, Conforti ML, et al. Intravenous immunoglobulins improve the function and ameliorate joint involvement in systemic sclerosis: a pilot study. Ann Rheum Dis. 2007;66(7):977-9.

2. Sandqvist G, Eklund M. Hand Mobility in Scleroderma (HAMIS) test: the reliability of a novel hand function test. Arthritis Care Res. 2000;13(6):369-74

3. Malcarne VL, Hansdottir I, McKinney A, et al. Medical signs and symptoms associated with disability, pain, and psychosocial adjustment in systemic sclerosis. J Rheumatol. 2007;34(2):359-67.

4. Dreiser RL, Maheu E, Guillou GB, Caspard H, Grouin JM. Validation of an algofunctional index for osteoarthritis of the hand. Rev Rhum Engl Ed. 1995;62(6 Suppl 1):43S-53S.

5. Roberts-Thomson AJ, Massy-Westropp N, Smith MD, et al. The use of the hand anatomic index to assess deformity and impaired function in systemic sclerosis. Rheumatol Int. 2006;26(5):439-44.

Sources of funding: None

Conflict of interest: None

Date of first submission: January 24, 2011

Last received: April 15, 2011

Accepted: April 20, 2011

\section{Address for correspondence:}

Thelma Larocca Skare

Rua João Alencar Guimarães, 796

Curitiba (PR) - Brasil

CEP $80310-420$

Tel. (+55 041) 3274-1659

E-mail: tskare@onda.com.br 


\title{
Confidential unit exclusion and blood safety
}

\section{Exclusão confidencial da unidade e segurança do sangue}

\author{
Seyed Moayed Alavian' \\ Baqiyatallah Research Center for Gastroneterology and Liver Diseases, Tehran, Iran
}

'MD, PhD. Professor of Gastroenterology and Hepatology, Baqiyatallah Research Center for Gastroenterology and Liver Diseases, Tehran, Iran.

\section{Dear Editor,}

I read with interest the article by Kasraian et al., recently published in your journal. ${ }^{1}$ They concluded that because of the higher prevalence of HBS, HCV and HIV positivity among blood donors who chose the confidential unit exclusion (CUE) option, offering CUE to blood donors could be a potentially useful method for improving blood safety, since it could increase the detection of infected blood during the window period.

I would like to open the issue for further discussion. Iran is an area of low endemicity for HCV infection, and the most common risk factors are histories of blood transfusion and intravenous addiction. ${ }^{2,3}$ However, for HBV infection, the most common risk factor is transmission during childhood, and most HBV-infected patients are unaware of their infection. ${ }^{4}$ Donor selection is an important strategy for blood safety, but it is not enough! CUE, in which the physician asks the donor whether he or she wants his/her blood to be used for transfusion or not, has been added in order to obtain safer blood and blood products. The donor is asked to choose "Use my blood" if he/she has given truthful answers to the questions and, if the questions have not been answered truthfully, is asked to choose "Do not use my blood". Although applying additional policies to maintain safety may lead to more donor rejection and to the exclusion of more blood for transfusion, these policies may vary for each region. Donor screening through physician assessment is still one of the most important components contributing towards providing healthy blood and blood products. The effectiveness of this CUE policy has been unclear. In a study performed by Kean et al. in the United States, $50 \%$ of the donors who chose "Do not use my blood" had made this choice mistakenly or due to lack of knowledge about this choice. ${ }^{5}$

Finally, I think that the effectiveness of confidential self-exclusion (CSE) systems depends on the risk factors for transfusion-transmitted infections and the educational level of blood donors in each country. 


\section{REFERENCES}

1. Kasraian L, Tavasoli A. Positivity of HIV, hepatitis B and hepatitis $C$ in patients enrolled in a confidential self-exclusion system of blood donation: a cross-sectional analytical study. Sao Paulo Med J. 2010;128(6):320-3.

2. Alavian SM, Ahmadzad-AsI M, Lankarani KB, et al. Hepatitis C infection in the general population of Iran: a systematic review. Hepatitis Monthly. 2009;9(3):211-23. Available from: http://hepatmon.com/ pdf/Hepatitis_C_Infection_in_the_General_Pop.pdf. Accessed in 2010 (Mar 31).

3. Alavian SM, Gholami B, Masarrat S. Hepatitis C risk factors in Iranian volunteer blood donors: a case-control study. J Gastroenterol Hepatol. 2002;17(10):1092-7.

4. Nokhodian Z, Kassaian N, Ataei B, et al. Hepatitis B markers in Isfahan, Central Iran: a population-based study. Hepatitis Monthly. 2009;9(1):12-6. Available from: http://hepatmon.com/pdf/ Hepatitis_B_Markers_in_Isfahan_Central_I.pdf. Accessed in 2010 (Mar 31).

5. Kean CA, Hsueh Y, Querin JJ, Keating LJ, Allensworth DD. A study of confidential unit exclusion. Transfusion. 1990;30(8):707-9.

Sources of funding: None

Conflict of interest: None

Date of first submission: March 3, 2011

Last received: March 3, 2011

Accepted: April 12, 2011

\section{Address for correspondence:}

Seyed Moayed Alavian, MD

Professor of Gastroenterology and Hepatology

Director of Baqiyatallah Research Center for Gastroenterology and Liver

Disease

Tel/Fax: +98 21 88945186-8, +982181262072

Postal Address: P.O. Box 14155/3651, Tehran, Iran

E mail: alavian@thc.ir 